\title{
Situações de leitura da literatura
digital na primeira infância: características da leitura independente, entre pares e compartilhada com os pais
}

Aline Frederico* Roberta Gerling Moro*

\section{Resumo}

O objetivo deste trabalho é analisar comparativamente a leitura de aplicativos literários na primeira infância nas situações de leitura independente, entre pares e compartilhada com os pais. Os dados provêm de dois estudos qualitativos que investigaram a resposta infantil na leitura digital. $\mathrm{O}$ primeiro estudo observou seis famílias de crianças de 4 anos residentes na Inglaterra, durante a prática de leitura compartilhada dos aplicativos Little Red Riding Hood (2013) e The Monster at the End of This Book (2011). O segundo estudo observou duas famílias com crianças de 3 a 7 anos no Brasil, lendo Petting Zoo (2013) e Chomp (2016), durante práticas de leitura individual e de leitura entre pares/irmãos. Quatro aspectos foram analisados: a linearidade da leitura, a exploração das funções interativas, a incidência de frustração e os padrões de comunicação verbal.

Palavras-chave: Leitura literária digital. Situações de leitura. Compartilhamento de leitura. Leitura independente. Literatura infantil digital.

\section{Introdução}

A literatura digital é um ponto de encontro entre literatura e tecnologia, em que as possibilidades e limitações do meio digital são exploradas para a criação de novas formas poéticas. Ela apresenta múltiplas facetas, abarcando diferentes gêneros e formatos, e sendo fortemente marcada pelas materialidades e possibilidades técnicas do dispositivo por meio da

\footnotetext{
Pós-doutoranda no Programa de Estudos Pós-Graduados em Literatura e Teoria Literária da Pontifícia Universidade Católica de São Paulo (PUC-SP). Bolsa de doutorado pleno Capes/Cambridge Trust , bolsa de pós-doutorado do Plano Nacional de Pós-Doutorado da Capes. E-mail: dr.aline.frederico@gmail.com

* Doutoranda no Programa de Pós-Graduação em Informática na Educação da Universidade Federal do Rio Grande do Sul (UFRGS). Bolsa de mestrado do Programa de Suporte à Pós-Graduação de Instituições de Ensino Particulares da Capes (1596104/2016-03) e bolsa de doutorado do Programa de Excelência Acadêmica da Capes (1812752-12/2018). E-mail: robmoro@ gmail.com
}

Data de submissão: abr. 2019 - Data de aceite: jul. 2019 http://dx.doi.org/10.5335/rdes.v15i2.9249 
qual é lida. No que se refere à literatura infantil digital, um dos formatos mais relevantes na última década é o dos aplicativos literários para dispositivos móveis com tela sensível ao toque, como tablets e smartphones. Aplicativos literários podem apresentar textos de diversos gêneros, narrativos e não narrativos, ficção e não ficção, poesia e prosa. Essa produção literária é marcada pela interatividade e participação do leitor, interferindo e coconstruindo sua dinâmica e poética; e por sua multimodalidade ${ }^{1}$.

O processo de leitura apresenta três importantes variáveis, o leitor, o texto, e o contexto (SIPE, 1999). Esses três elementos estão fortemente relacionados, e as características de cada um individualmente influenciam profundamente a experiência literária como um todo. Uma vez que o texto dos aplicativos literários apresenta características bastante particulares, a dinâmica da leitura tende a ser bastante específica. Já o contexto é um conceito amplo, que envolve aspectos culturais, sociais e econômicos complexos. Ainda que o contexto seja uma construção abstrata, ele se manifesta nas situações de comunicação, o que facilita a sua investigação (HALLIDAY, 1978). Um dos aspectos centrais dos contextos de leitura são as diversas formas de compartilhamento: a leitura individual e independente, a leitura em voz alta em grupo, a leitura compartilhada com o professor, com colegas, com os pais, com familiares, etc. Neste artigo, denominamos "situações de leitura" esses contextos de compartilhamento.

Na primeira infância, a leitura tende a ser fortemente mediada por pais e educadores e a situação da leitura compartilhada com os pais é uma das formas pela qual a mediação no contexto doméstico ocorre. A leitura compartilhada com os pais tende a ser vista tanto como uma forma de promover e dar suporte aos pequenos leitores que ainda não dominam o código escrito, mas, também, como uma atividade prazerosa de troca de ideias, valores e afetividade entre pais e filhos (FITTIPALDI; RIVAS, 2010).

Já a leitura literária digital, na sua qualidade de experiência híbrida, se relaciona e é influenciada pelas experiências com a literatura tradicional, mas, também, por outras experiências estéticas e educacionais no meio digital. No que se refere ao uso compartilhado da tecnologia móvel na primeira infância, uma visão bastante difundida no senso comum e fortemente alimentada pela mídia ${ }^{2}$, indica que muitos pais utilizam os dispositivos móveis para envolver e distrair as crianças enquanto estão ocupados. No entanto, as pesquisas sobre o uso doméstico de tecnologia na infância indicam uma forte preocupação dos pais com a segurança dos filhos, e que o uso acompanhado, ainda que não necessariamente compartilhado ${ }^{3}$, parece ser bastante comum. 
Um dos poucos estudos a comparar a leitura em formato impresso e o uso de tecnologia, tanto de maneira autônoma quanto compartilhada, foi feito no Reino Unido por Natalia Kucirkova e Karen Littleton (2016, dados de 2015). O estudo envolveu 1511 pais de crianças de 0 a 8 anos e investigou a leitura compartilhada e individual e o uso compartilhado e individual da tecnologia. Os resultados mostram semelhanças entre as práticas de leitura e o uso da tecnologia: $82 \%$ dos pais reportaram realizar a leitura compartilhada com seus filhos e 79\% reportaram o uso compartilhado da mídia digital. Já no caso da experiência autônoma, $51 \%$ dos pais disseram que seus filhos leem de maneira independente todo dia ou quase todo dia; já $51 \%$ dos pais indicaram que suas crianças usam a mídia digital sozinhas em algumas ocasiões.

Mais comumente, os estudos focam no uso acompanhado da tecnologia como forma de supervisão parental, com o fim de evitar usos indevidos e perigos relacionados à comunicação pela internet. A única pesquisa quantitativa sobre uso de tecnologia móvel na infância realizada no Brasil, focada no uso de smartphones, aponta que entre os $84 \%$ das crianças de 4 a 6 anos que tem acesso a smartphone $^{4}, 33,5 \%$ dos pais disseram ficar sempre "ao lado do seu filho(a) observando e controlando o que ele(a) faz no smartphone", enquanto $42,7 \%$ dos pais disseram fazer esse controle na maioria das vezes (PANORAMA MOBILE TIME; PAIVA, 2018).

Esses dados apontam que tanto as experiências autônomas de leitura e de uso de mídia digital, como as compartilhadas, são bastante frequentes na infância. No entanto, pouco se sabe sobre as diferenças qualitativas entre as experiências de leitura literária digital individual e compartilhada. Esse artigo compara os dados de duas pesquisas que analisaram a recepção e a construção de sentido na leitura de aplicativos literários na primeira infância. $\mathrm{O}$ primeiro estudo observou crianças de diversas origens vivendo na Inglaterra enquanto liam aplicativos literários de maneira compartilhada com pelo menos um dos pais, em uma biblioteca pública (FREDERICO, 2018), enquanto o segundo observou crianças brasileiras lendo em casa aplicativos de maneira independente $^{5}$ ou em leitura compartilhada entre irmãos (MORO, 2018). Ao comparar as observações da leitura digital em diferentes situações, esse artigo pretende, portanto, responder à seguinte pergunta de pesquisa:

Quais são as semelhanças e diferenças entre a leitura de aplicativos literários nas situações de leitura independente, de leitura compartilhada com os pais e de leitura compartilhada entre pares na primeira infância? 


\section{Desdobramentos das diferentes situações de leitura}

Para além das características e propriedades do texto literário, as diferentes situações de leitura influenciam o desenvolvimento da leitura, sua experiência e os aprendizados, implícitos e explícitos, que aí podem ocorrer. Natalia Kucirkova, Karen Littleton e Teresa Cremin indicam que o compartilhamento social é uma das facetas fundamentais da leitura digital na infância: "A leitura é uma prática social, no sentido que o prazer do leitor no engajamento com a narrativa é ampliado pela possibilidade de compartilhar essa experiência com outras pessoas" (2016, p. 8). No entanto, esse compartilhamento não precisa necessariamente ocorrer durante a leitura.

Muitos autores apontam para os benefícios estendidos do acompanhamento da experiência digital por adultos. Por exemplo, Kathy Hirsh-Pasek et al. (2015) investigaram um grande corpus de aplicativos para crianças que apresentavam a bandeira de "educativos" concluem que em grande parte dos casos, os aplicativos demonstram um grande desconhecimento sobre como o aprendizado ocorre, de acordo com as evidências científicas. Um dos "pilares" do processo de aprendizado, segundo os autores, seria a interação social. Relações sociais são uma forma natural de aprendizagem e o aprendizado que acontece com e por intermédio de outras pessoas seria mais efetivo. Essa perspectiva ecoa em grande parte da investigação da prática de leitura compartilhada na infância, que indica que a leitura compartilhada afeta diretamente o desenvolvimento da linguagem, da alfabetização e do letramento emergentes e da capacidade leitora (por exemplo, BUS; VAN IJZENDOORN; PELLEGRINI, 1995). No entanto, é preciso levar em conta que a leitura compartilhada é uma prática fortemente associada a determinadas culturas, classes e grupos sociais, como ressaltam Heath (1983) e van Kleeck, Stahl, e Bauer (2003), o que pode relativizar esses resultados em contextos como o brasileiro.

Por outro lado, há quem questione que o compartilhamento com um adulto seja fundamental para o aprendizado por meio da leitura digital: Zsofia K. Takacs, Elise K. Swart e Adriana G. Bus (2014) realizaram um meta-estudo comparando a leitura independente digital com a leitura compartilhada de livros impressos e sugerem não haver diferenças de compreensão e ganho de vocabulário. As autoras indicam que as funções multimídia dos aplicativos podem, portanto, substituir o adulto na leitura literária, sem prejuízo ao aprendizado. Cristina Aliagas e Ana María Margallo (2015) realizaram um estudo 
etnográfico na Espanha com crianças de 1 ano e 11 meses a 5 anos e 5 meses lendo aplicativos literários no ambiente doméstico. Elas indicam uma ponte entre a leitura compartilhada e a individual, em que, inicialmente, a leitura era mais explicitamente guiada pelos pais, que seguravam e controlavam o dispositivo. Com o passar do tempo, algumas crianças demandaram um progressivo controle sobre a leitura, culminando na leitura independente. As autoras ressaltam que tal desenvolvimento diz respeito não apenas ao letramento tecnológico, ou à capacidade de a criança operar o dispositivo e os aplicativos, mas, também, seu letramento literário, desenvolvendo ao longo do tempo sua capacidade de compreensão das narrativas interativas.

Enquanto a pesquisa sobre a leitura compartilhada é significativamente extensa, a investigação sobre a leitura independente é mais rara. Sherry Sanden (2012) investigou a leitura independente em sala de aula e aponta que, nas classes observadas, as crianças costumavam ter autonomia para selecionar os títulos e escolher seu lugar para a leitura. Os estudantes podiam ainda estabelecer tópicos de interesse a partir das obras escolhidas, sendo que, com esta oportunização, os professores encorajavam as crianças à leitura de diferentes textos, buscando por outras fontes de pesquisa. Ainda que em alguns momentos a professora estivesse presente, para sugerir e tirar dú- vidas, a expectativa das crianças era de uma leitura sem a supervisão constante, desejando interagir com o texto por conta própria. De acordo com a pesquisadora, a prática de leitura independente é uma importante oportunidade para a promoção da aprendizagem direta ou indireta da leitura por meio do envolvimento dos estudantes com o texto. Além disso, o constante incentivo da leitura independente pelos professores, pode possibilitar a resolução das inconsistências de leitura dos próprios leitores. Assim, esse tipo de prática viabiliza o empenho durante a leitura, especialmente por seu caráter instrucional e exploratório.

Em se tratando da leitura independente de aplicativos literários, Neus Real e Cristina Correro (2015), compararam, num estudo longitudinal de dois anos de duração na Espanha, a experiência literária digital de crianças pré-escolares em casa e na escola. Enquanto na escola a leitura literária era bastante mediada pelo educador, em casa as crianças preferiram ler e descobrir os elementos do dispositivo de forma independente. Entretanto, a participação dos pais ainda se via presente, especialmente na medida em que mediavam o tempo em que as crianças permaneciam imersas no dispositivo. Ao longo do tempo, as crianças retornavam aos mesmos aplicativos, mas a leituras subsequentes se revelaram bastante fragmentadas. Incidentes de frustração também foram observados, e 
frequentemente levavam à interrupção da leitura e à mudança brusca de um aplicativo para o outro.

Já no que diz respeito à pesquisa sobre a leitura entre pares, as referências são ainda mais escassas. Uma exceção é o trabalho de Fiona Maine (2015), que investiga a relação dialógica que ocorre quando duas crianças do mesmo ano escolar leem juntas textos multimodais diversos na escola ${ }^{7}$. A análise indica que quando as crianças constroem significados com seus iguais, sem a interferência de um adulto, elas devem alinhar o aspecto interpessoal, que se refere a seus conhecimentos, habilidades e expectativas, com $o$ aspecto interpessoal, que envolve as interações entre os leitores e o desenvolvimento de uma proposta conjunta. Se desenrola, portanto, um "espaço de possibilidades" (p. 19-20) entre os leitores e entre o leitor e o texto, em que os significados são temporários, negociáveis e negociados. Diferentemente da leitura compartilhada com um adulto, em que o adulto apresenta uma autoridade e um conhecimento dito mais avançado para avaliar os comentários e ações da criança durante a leitura, possivelmente validando-os como "certos ou errados" dentro do seu próprio referencial, na leitura entre pares, existe uma igualdade entre leitores. Essa simetria pode levar a uma colaboração mais equânime na co-construção dos significados. A leitura entre pares observada por Maine indica que as crianças usam essa estrutura dialógica tanto para a reflexão crítica quanto criativa, usando o texto como plataforma para a criação de outros mundos e histórias para explicar elementos do texto.

\section{Metodologia}

A análise e discussão apresentadas nesse artigo são resultado do cruzamento e da comparação de dados qualitativos de dois projetos que envolveram estudos de casos com crianças lendo aplicativos literários.

O primeiro projeto (Estudo 1) realizou estudos de caso com seis famílias de crianças de 4 anos residentes no Reino Unido (Amelia, Emme, Lukas, Maria, Molly e Roza). Todas as crianças tinham contato moderado com a tecnologia móvel, contato em geral fortemente mediado pelos pais. Todos eram leitores frequentes de livros impressos e frequentadores de bibliotecas públicas, porém apenas uma das participantes já havia lido aplicativos literários com um alto nível de interatividade, como os apresentados na pesquisa. Entre os aplicativos usados na pesquisa, nesse artigo serão analisadas as respostas leitoras a Little Red Riding Hood [Chapeuzinho vermelho] (2013), ilustrado por Ed Bryan e produzido pela editora inglesa Nosy Crow e a The Monster at the End of This Book [O monstro no fim do livro] (2011), 
escrito por Jon Stone, ilustrado por Michael Smollin e publicado pela Sesame Workshop, produtora da Vila Sésamo nos EUA. A pesquisa foi aprovada pelo conselho de ética da Faculdade de Educação da Universidade de Cambridge e seguiu as recomendações éticas da British Educational Research Association (BERA, 2011), com consentimento escrito por parte dos pais participantes e consentimento verbal por parte das crianças.

O segundo projeto (Estudo 2), por outro viés, realizou práticas de leitura com três famílias de crianças de 3 a 10 anos residentes no Brasil. As leituras ocorreram na casa dos participantes e as famílias tinham contato prévio com a pesquisadora, o que permitiu uma maior abertura e acolhimento em suas residências. No estudo, foram realizadas sessões de leitura com oito aplicativos literários, em função da diferença de idade e nível de alfabetização e letramento digital dos grupos de leitores. Neste trabalho, com o fim de comparar a leitura na primeira infância, optou-se pela análise dos dados relativos às práticas de leitura dos aplicativos Petting Zoo [Mini Zoo] (2013) e Chomp (2016), do ilustrador Christoph Niemann e publicados pela Fox and Sheep, por duas das famílias: a primeira família com uma criança de 3 anos (Gabriel), e a segunda, com duas crianças, uma de 4 anos (Elena) e uma de 7 anos (Isabella). As famílias tentavam dedicar algum tempo à leitura literária fora do ambiente escolar, seja por meio de contações de histórias, visitas à biblioteca pública da cidade ou compra de livros em livrarias. Em contrapartida, os participantes nunca tiveram acesso aos aplicativos literários, sendo que a criança de 3 anos tinha experiências mais avançadas com a tecnologia digital (jogos, vídeos e séries de desenhos animados), enquanto a outra família restringia o acesso das crianças aos dispositivos digitais, incentivando a leitura literária impressa e realização de atividade físicas e culturais fora de casa. A pesquisa foi aprovada pelo Comitê de Ética da Universidade Luterana do Brasil ${ }^{8}$, cumprindo, portanto, os requisitos éticos propostos para a pesquisa com crianças.

Os métodos de coleta de dados dos dois estudos envolveram gravações audiovisuais e registros escritos da observação das crianças em interação com os aplicativos, assim como entrevistas semiestruturadas sobre as práticas de leitura e uso da tecnologia pelas famílias, a fim de mapear o perfil dos participantes.

A situação de leitura compartilhada com os pais foi, prioritariamente, observada no Estudo 1. Já as situações de leitura independente e leitura compartilhada entre pares foram propostas e observadas no Estudo 2. Gabriel leu os aplicativos Petting Zoo e Chomp de maneira independente, ainda que a leitura de Chomp tenha sido marcada por momentos em que os pais interferiram, 
se convertendo parcialmente em uma leitura compartilhada. Já Elena leu independentemente o aplicativo Chomp. Finalmente, a leitura entre pares ocorreu entre as irmãs Elena e Isabella, que leram os dois aplicativos, Petting Zoo e Chomp.

Ainda que os dados já tivessem sido analisados nos estudos originais, uma vez que o objetivo desses estudos iniciais não era a comparação das situações de leitura, um novo processo de análise foi realizado. Um processo inicial de redução da amostragem foi elaborado, em que cada pesquisadora, por conhecer profundamente os dados referentes ao seu estudo, selecionou um corpus reduzido de vinhetas, trechos de 20 segundos a 3 minutos e 20 segundos dos eventos de leitura em que estavam salientes características interpretadas como críticas da situação de leitura em questão. Um corpus de 20 vinhetas, sendo 10 vinhetas de leitura compartilhada, 7 vinhetas de leitura individual, e 5 vinhetas de leitura compartilhada entre irmãos, foi então analisado comparativamente. $\mathrm{O}$ processo de análise envolveu a vista repetida de todas as vinhetas pelas pesquisadoras e um processo de registro dos temas emergentes da comparação das situações de leitura. Os temas emergentes levantados foram:

1. A linearidade/não linearidade da leitura - A leitura seguiu sua sequência lógica? Houve inter- rupção na leitura ou saltos de cenas/interações fundamentais?;

2. A exploração do leitor do potencial interativo das cenas - $\mathrm{O}$ leitor permaneceu na cena até a conclusão das interações principais, sem as quais o sentido da leitura fica prejudicado? O leitor explorou amplamente as possibilidades interativas das cenas?;

3. Incidentes de frustração - Houve incidentes em que a criança demonstrou frustração no desenrolar da leitura?;

4. Padrões de comunicação verbal - Quem se comunicou verbalmente? Para que foi usada a linguagem verbal no contexto da leitura?

As vinhetas selecionadas foram então re-submetidas à análise de acordo com os temas e questões levantados. Para validar os resultados obtidos com a análise das vinhetas em relação à totalidade dos dados, esses resultados foram contratados com os eventos de leitura completos e alguns dos resultados foram relativizados de acordo.

É importante, no entanto, indicar que se trata de uma análise qualitativa e que os resultados encontrados indicam tendências observadas nos dados. Cada evento de leitura discutido é único, situado temporal e espacialmente, e, portanto, não apresenta padrões universais. Além disso, dentro de um mesmo evento há 
variações nos padrões e estilos de leitura, bem como nas atitudes e respostas dos leitores.

\section{Os aplicativos}

Little Red Riding Hood (2013) é um aplicativo que faz uso dos recursos da mídia digital para contar sua versão do conto de fadas clássico da Chapeuzinho Vermelho. Nessa versão, o leitor atua como ajudante da Chapeuzinho, ajudando-a a empacotar a cesta para a vovó, a coletar objetos na floresta, entre outras atividades. O leitor deve ainda decidir por que caminhos seguir na floresta e a cada bifurcação um objeto é coletado e outro caminho deixa de ser explorado. Para coletar os objetos, o leitor deve participar de breves jogos interativos. Quando atacada pelo Lobo, Chapeuzinho usa os objetos coletados para atacá-lo, e a história apresenta três finais distintos dependendo das escolhas do leitor durante o percurso. Em todos os finais, no entanto, o Lobo é derrotado. Chapeuzinho então destranca a Vovó do armário e com ela toma o lanche da tarde. $\mathrm{O}$ aplicativo demanda o uso de diversos gestos interativos, muitos deles mais complexos do que os simples tocar e arrastar.

Já o aplicativo The Monster at the End of This Book (2011) é baseado no álbum ilustrado homônimo de 1971. Nessa história, Grover, um personagem da Vila Sésamo, pede ao leitor que não vire as "páginas" do "livro" que está lendo, pois Grover tem medo de monstros e há um monstro no fim do livro. Para continuar a história, no entanto, o leitor deve continuar virando as páginas, contrariando Grover, que fica, progressivamente, mais desesperado com a aproximação do monstro. Grover, então, constrói barreiras para impedir que o leitor vire as páginas, mas o leitor tem o poder de destruir os bloqueios por meio da interatividade. No fim do livro, a surpresa: o monstro nada mais é do que o próprio Grover. Nesse aplicativo, todo o texto é em formato de diálogo entre Grover e o leitor. As interações são bastante definidas em cada cena, em muitos casos focada no gesto de virar a página, e em algumas cenas, é estendida pelas ações de destruição dos bloqueios. Caso o leitor não saiba como interagir, a personagem apresenta, em forma de ironia, "dicas" do que "não" fazer.

Petting Zoo (2013) é uma criação visual do artista Christoph Niemann que combina desenhos animados e fotografias. Nesse aplicativo, o leitor precisa interagir com as personagens (animais), que respondem com uma ação. Ao passar o dedo em certas direções nas cenas, ou apenas tocando sobre a tela, diferentes reações são geradas nas personagens. Ao todo são 21 animais com os quais é possível interagir. Nesse aplicativo, não há texto verbal, mas a comunicação das personagens com o leitor é bastante mar- 
cada pelas ações dos desenhos e efeitos sonoros. De uma forma geral, o modo de interagir com os animais é simples, mas demanda a todo o momento uma ação a ser tomada pelo leitor. Caso o leitor demore para interagir, o próprio aplicativo "desenha" pistas na tela, indicando quais gestos realizar.

Em continuidade à sua produção artística, Christoph Niemann elaborou um novo aplicativo, Chomp (2016), o qual possibilita que o leitor insira seu rosto na narrativa. Dessa forma, o leitor é uma espécie de "copersonagem" e participa utilizando suas expressões faciais, abrindo-se a diferentes criações e interpretações. Utilizando a câmera do dispositivo, os leitores inserem seus rostos em 52 cenas, podendo se transformar, instantaneamente, em super-herói, máquina de lavar roupa, relógio, um pedaço de torrada e, através do toque sobre a tela, é possível animar os desenhos e criar falas e expressões faciais. $\mathrm{O}$ aplicativo então permite que o leitor esteja em variados cenários e se adapte à personagem que desejar. Nesse sentido, há um esforço por parte do autor e desenvolvedores em incentivar o leitor a utilizar as ilustrações como pano de fundo para sua própria imaginação, dando "vida" aos desenhos. $\mathrm{O}$ aplicativo atua na mesma lógica de Petting Zoo ao não utilizar o texto verbal como forma de comunicação e progressão da história; somente é possível visualizar as ilustrações e o rosto do leitor na tela, acompanhados dos respectivos efeitos sonoros.

\section{Análise e resultados}

\section{Linearidade da leitura}

Todos os aplicativos lidos pelas crianças apresentam uma forma de navegação primordialmente linear, em que uma cena leva sempre à mesma cena seguinte. A possibilidade de leitura não linear existe por meio do menu de navegação, em que os leitores podem escolher uma cena e saltar livremente de uma cena a outra. Enquanto os aplicativos do Estudo 1, Little Red Riding Hood e The Monster at The End of This Book, apresentam uma estrutura narrativa, que em teoria fomenta uma leitura linear pois existe um encadeamento lógico dos fatos e acontecimentos, os aplicativos Petting Zoo e Chomp não apresentam um arco narrativo, o que pode sugerir ao leitor a possibilidade de uma leitura não linear, já que a ordem das cenas não interfere na experiência literária. Petting Zoo, no entanto, apresenta transições animadas entre uma cena e outra: ao tocar na seta, não há uma simples mudança de cena, mas uma animação que transforma uma cena na seguinte, mantendo um fio condutor entre elas. Esse recurso, portanto, é parte significativa da leitura dessa obra e também sugere uma leitura linear. 
Frente a essas características das obras, os eventos de leitura compartilhada (Little Red Riding Hood e The Monster at the End of This Book) foram marcadamente leituras lineares. A possibilidade de pular de cena por meio do menu de navegação não foi explorada durante a primeira leitura de cada obra, tendo sido usada apenas como recurso na releitura, quando a criança desejou voltar à(s) sua(s) cena(s) favorita(s). Mas mesmo em casos de releitura, o leitor preferiu inicialmente reler a obra inteira de forma linear, para só então navegar livremente e repetir suas cenas favoritas. Em alguns incidentes isolados, em que a criança realizou algum salto na narrativa, mudando de cena antes de realizar a interação cardinal, os pais rapidamente intervieram, voltando à cena anterior e retomando a linearidade da história. Esse tipo de intervenção pôde ser visto, por exemplo, quando Molly lia a cena em que deve encontrar a chave para soltar a vovó que se encontra presa dentro do armário (Little Red Riding Hood). Na busca pela chave que abre o armário em que se encontra a Vovó, Molly recorre a uma série de gestos exploratórios, tocando os objetos visíveis no ambiente. Sem encontrá-la e na tentativa de seguir com a história, Molly toca na seta que passa para a cena seguinte, mas essa cena já é o fim da história, em que se lê na tela as palavras "The End" ["Fim"]. A mãe de Molly, Abby, intervém, retomando a linearidade da narrativa. Ao perceber que houve um salto na narrativa, ela diz: "Hang on, let's find the key. Let's take grandma out [of the wardrobe]." ["Espera um pouquinho, vamos achar a chave. Vamos tirar a vovó [do armário].”], apertando a seta para voltar à cena anterior.

No que diz respeito à leitura independente (Petting Zoo e Chomp), as leituras também foram predominantemente lineares e as crianças não perceberam ou não exploraram as possibilidades de não linearidade. De uma forma geral, as crianças não se sentiram instigadas a pular cenas. No caso de Petting Zoo, possivelmente, isso se deve ao efeito de transformação (metamorfose) das cenas ser relevante e interessante, assegurando o engajamento dos leitores na leitura linear. Isso ficou evidente quando Gabriel (3 anos) "zapeou" entre as telas do aplicativo Petting Zoo, observando o desenvolvimento visual de uma figura para a outra na transição das cenas. Já na leitura do aplicativo Chomp, também houve situações em que o menino zapeava de uma tela para a outra, sem explorar os recursos disponíveis, o que levou à interferência dos pais, que solicitavam que o menino retornasse a uma tela específica, que lhes havia chamado a atenção. Na releitura dos aplicativos, Gabriel priorizou a leitura de algumas cenas de sua preferência, mas mesmo nesse caso realizou a navegação de maneira linear, sem utilizar o menu de 
navegação, que ele pareceu desconhecer. Ele então zapeava rapidamente até a cena desejada e interagia com ela mais extensamente.

A linearidade da leitura também foi observada na leitura compartilhada entre as irmãs Elena e Isabella. Nesse caso, faz-se destaque à cooperação entre elas e o acordo implícito de que a leitura deveria avançar somente quando ambas finalizassem a interação com a cena. Além disso, a transição entre as cenas em Petting Zoo também foi motivo de atenção e as irmãs tentaram repetidas vezes interagir com as animações da transição, ainda que este recurso não estivesse disponível. Isso ressalta como as transições podem ter tido um efeito determinante na manutenção da linearidade da leitura, já que as crianças pareciam ler o aplicativo como uma única cena.

\section{A exploração das funções interativas}

$\mathrm{Na}$ grande maioria das cenas dos quatro aplicativos, há a possibilidade de o leitor realizar mais de um tipo de interação, resultando em diferentes efeitos e acontecimentos na cena. Assim, as obras convidam os leitores a se deter por alguns instantes para desvendar suas possibilidades e assim estender o potencial estético da obra. De acordo com Ture Schwebs (2014), a partir dos tipos de eventos narrativos propostos por
Roland Barthes (1984), as interações que provocam eventos na narrativa podem ser classificadas em "cardinais"/"essenciais”, quando envolvem uma ação ou acontecimento que é central na narrativa, ou "catalisadoras"/satélites", quando produzem eventos secundários e facultativos, cuja eliminação não afeta o enredo. Ambos tipos de interação são importantes na experiência estética da leitura digital, mas as interações cardinais são essenciais para a compreensão da história. Nos aplicativos do Estudo 1, Little Red Riding Hood e The Monster at the End of This Book, que possuem uma narrativa, os dois tipos de interatividade estão presentes. Já para os aplicativos do Estudo 2, Petting Zoo e Chomp, uma vez que não há arco narrativo, essa classificação não se aplica: ainda que nenhuma interação represente uma função cardinal em relação à obra como um todo, elas não são dispensáveis à leitura, exatamente, porque a essência da experiência literária dessas obras é gerar e explorar eventos satélites com funções lúdicas e até cômicas.

Assim, entre os participantes no modo de leitura compartilhada no Reino Unido, na grande maioria dos casos, os leitores permaneceram em cada uma das cenas até completar as interações cardinais, mesmo quando estas se revelaram desafiadoras. Os pais, acompanhando cada passo do leitor infantil, realizavam avaliações e intervenções constantes, ao 
mesmo tempo que eles próprios, por estarem lendo as narrativas pela primeira vez, buscavam fazer sentido da história e compreender o que era esperado do leitor. Como resultado desse acompanhamento, os pais incentivaram as crianças a explorar quando essas não o faziam espontaneamente ou corrigiam/davam suporte à criança quando ela apresentava dificuldade com a interação. Esse tipo de compartilhamento ficou bastante visível, por exemplo, quando as crianças estavam lendo pela primeira vez a obra The Monster at the End of This Book. Essa era também a primeira vez que a maioria das crianças lia um aplicativo literário altamente interativo, e quando chegaram à primeira cena em que a personagem bloqueia as páginas do livro, amarrando-as com cordas, muitos leitores infantis tentaram virar a página sem desamarrar as cordas. Os pais então incentivaram a criança a refletir sobre suas ações, perguntando, por exemplo, "What can you do?" ["O que você pode fazer?”] (Bea perguntando a Roza), ou indicando dicas no próprio texto que sugerem onde interagir, chamando a atenção da criança aos círculos amarelos que aparecem ao redor dos hotspots: "Can you see the knots there? Can you see where they were flashing? And how you try and do / undo the knots?" ["Você está vendo os nós? Está vendo que eles estão piscando? Que tal você tentar desfazer os nós?] (Abby falando com Molly).
Já na leitura independente, houve variação na permanência do leitor nas cenas e na exploração das possibilidades interativas, de acordo com o aplicativo lido. Em Petting Zoo, houve uma rápida familiarização com os recursos de interação, o que permitiu que Gabriel explorasse durante mais tempo algumas cenas específicas, estabelecendo suas preferências individuais: na cena do tigre e da borboleta, ele foi bastante persistente tentando fazer com que o tigre caçasse a borboleta, mesmo que essa ação não estivesse prevista na obra.

Em Chomp, um dos elementos centrais da interação diz respeito ao posicionamento da imagem do rosto do leitor, captada pela câmera frontal do aparelho. Desse modo, o leitor passa a "incorporar" as personagens e a interpretá-las, e ao mesmo tempo se vê "manipulado" digitalmente pela narrativa, que usa sua imagem com finalidade poética. Essa função, no entanto, exige que o leitor posicione 0 aparelho a uma distância exata de seu rosto, o que representou uma certa dificuldade para os leitores infantis. No caso de Gabriel, ele passou então a interagir com o aplicativo sem posicionar o rosto e focando nas animações e mudanças nas cenas que resultavam de suas interações.

Desse modo, uma parte importante da obra estava sendo perdida, o que levou os pais a intervirem na leitura individual de Gabriel, para ajudá-lo. Em conjunto com os pais, portanto, a criança 
descobriu como posicionar o rosto na narrativa, visto que nos momentos subsequentes em que realizou a leitura do mesmo aplicativo, ele soube posicionar o rosto sem a intervenção dos pais. Uma vez aprendido o posicionamento, Gabriel passou a zapear rapidamente entre as telas, sem explorar amplamente as ações interativas que deveriam ser tomadas durante a leitura de cada cena. Esse comportamento do leitor infantil levou, mais uma vez, à intervenção dos pais na leitura individual, já que a criança não explorava por completo as interações de cada tela. Assim, a intervenção dos pais propiciou que Gabriel retornasse à tela anterior e explorasse os recursos de forma completa, sem se restringir a apenas um toque sobre a tela e logo pular para a próxima cena. Isso ocorreu, por exemplo, na cena de Chomp em que o leitor tenta alimentar a personagem/a si próprio. Ao tocar sobre a tela, o leitor lança um alimento com uma colher. Aleatoriamente, o efeito pode ser de o alimento acertar a boca da personagem, mas a comida pode ainda atingir o olho ou passar direto por acima da cabeça. Enquanto na leitura individual, Gabriel não se deteve a ponto de explorar essas opções, ao ouvir aos questionamentos e sugestões dos pais (“Toca para ver o que acontece!”; “Coloca na boca!”), a criança pôde reagir a todas as animações propostas pela narrativa, assumindo, quase que de forma física, o papel da personagem.
De forma semelhante, quando Elena leu de maneira independente esse aplicativo, teve dificuldade em posicionar o rosto e deixou de explorar algumas interações. Para promover uma leitura mais completa da obra, a pesquisadora interveio em alguns momentos. Houve situações, por exemplo, em que a criança apenas deleitava-se com a imagem de seu rosto no corpo das personagens, passando rapidamente de uma tela para outra. No entanto, quando finalmente despertou para os recursos de interação, Elena realizou as interações repetidamente, interagindo diversas vezes em cada cena da obra.

Por fim, na leitura compartilhada entre as irmãs com o aplicativo Petting Zoo, uma reação de "imobilização" foi constatada. A posição corporal das crianças, bem como a desorientação inicial devido à timidez e pouca experiência com dispositivos móveis pode ter ocasionado o pouco envolvimento num primeiro momento. Uma vez que as irmãs não manifestaram nenhuma reação frente aos recursos da narrativa, nem ao menos tentaram tocar o dispositivo de forma exploratória, a intervenção da pesquisadora foi fundamental para que as crianças pudessem explorar as cenas por completo, em que pequenas demonstrações (toque sobre a tela, por exemplo) foram realizadas para que elas se sentissem motivadas a interagir. Embora a diferença de idade prevalecesse em alguns momentos, as 
irmãs colaboraram para a exploração dos elementos interativos de cada cena, desenvolvendo em pouco tempo, autonomia em relação ao aplicativo.

Na leitura do aplicativo Chomp, cada criança assumiu um papel distinto na leitura: enquanto a irmã mais velha, Isabella, segurava o aparelho e realizava as interações, Elena guiava a leitura, indicando onde "apertar" (tocar) para gerar os efeitos de animação e/ou sonoros. Uma situação pode ser enfatizada quanto à intervenção da irmã: na cena do urso panda comendo as folhas de uma árvore, a menina solicitou que a irmã tocasse somente sobre o galho no qual o urso panda estava pendurado, repetindo diversas vezes: “Toca no galho!", ensinando a irmã como manusear o aplicativo, uma vez que ela já havia lido a história e sabia das diversas possibilidades de interação. Sendo que Elena mediava as interações de sua irmã, Isabella, os gestos e ações das crianças foram semelhantes, tanto em situações de leitura individual (Elena), como compartilhada, uma vez que Isabella baseava-se nas sugestões dadas pela irmã. Nesse sentido, a exploração das possibilidades interativas foi marcada pela criação de expressões faciais, de modo que Isabella parecia se envolver de forma lúdica e imaginativa com os recursos. Ainda que tenha havido a intervenção dos adultos (pais e pesquisadora) em alguns momentos, é importante ressaltar que esses aplicati- vos são longos e, de uma forma geral, os leitores exploraram significativamente 0 potencial interativo das cenas.

\section{Incidentes de frustração no desenrolar da leitura}

Para ler e interagir com essas obras de literatura digital, o leitor deve compreender a lógica de interação da obra. Por um lado, o leitor pode vislumbrar ações que gostaria de fazer e essas não estarem disponíveis e, por outro, o leitor tem que compreender exatamente o que deve fazer para que as possibilidades interativas se concretizem. Assim, a leitura digital pode gerar um certo nível de frustração no leitor, caso essa comunicação entre leitor e obra por meio da interação não ocorra de maneira fluída.

Na leitura compartilhada, as leituras se desenrolaram com certa facilidade, mas não porque os aplicativos eram necessariamente fáceis e intuitivos de usar, mas porque os pais intervieram com frequência quando desafios e dificuldades se apresentaram ao pequeno leitor. No caso de The Monster at the End of This Book, passado um momento inicial de familiarização com a leitura digital ocorrido nas primeiras cenas, pois era a primeira leitura desse tipo para quase todos os participantes, os leitores tiveram facilidade em identificar as interações, pois essas eram poucas e bastante óbvias dentro do contexto da história. Já na lei- 
tura de Little Red Riding Hood, em que as interações eram mais complexas tanto no que diz respeito à coordenação motora e o modo de realizar o gesto, quanto no que diz respeito à quantidade e às funções das interações, alguns momentos de frustração foram visíveis. Na maioria dos casos, os leitores optaram pela insistência, por continuar tentando até realizar a interação corretamente. Nessa atitude obstinada do leitor, no entanto, o suporte dos pais foi fundamental para a realização correta da interação.

Em apenas um caso a própria mãe, Becky, frustrada com a dificuldade em completar a interação, que exigia navegar uma aranha por um labirinto, decidiu por seguir com a história sem completá-la. Nesse exemplo, tanto a mãe como a criança, Amelia, ficaram, visivelmente, frustradas com a dificuldade de interação. Por outro lado, nos casos em que o leitor perseverou, apesar de momentos pontuais de frustração, o eventual sucesso na realização da interação levou a um notável sentimento de vitória e superação. Isso ocorreu, por exemplo, quando os leitores optaram, em Little Red Riding Hood, por seguir o caminho da música, culminando num jogo complexo em que o leitor deve repetir uma série de movimentos em sequência. A atividade apresentou um grande desafio para crianças de quatro anos, e tanto Maria como Emme, que jogaram essa cena, realizaram diversas tentativas para conseguir completá-la. Ao final, no entanto, Maria e seus pais celebraram com palmas e abraços, enquanto a mãe de Emme a parabenizou repetindo "Well done!"["Muito bem!"] e dando-lhe um beijo na cabeça. Portanto, as dificuldades, quando superadas com o suporte do adulto, se transformaram em um prazer expandido e um momento de aproximação e afetividade entre os coleitores.

Já os aplicativos do Estudo 2 apresentam maior facilidade para interagir, pois o simples toque no personagem central da cena provoca uma resposta do aplicativo. No Caso de Chomp, o toque pode ser realizado repetidas vezes com resultados variados que se alternam. Já em Petting Zoo, o leitor pode tocar ou deslizar o dedo em diferentes direções, e dependendo da direção, um efeito diferente pode ocorrer. Uma vez que gestos simples já provocam uma resposta no aplicativo e não há uma única maneira para interagir, os leitores, tanto na leitura independente como na entre pares, navegaram com bastante fluidez pelas cenas. Um dos poucos casos de frustração observados se referiu, principalmente, ao nível de interatividade proporcionado em algumas cenas. É o caso da leitura independente de Gabriel (Petting Zoo), em que a criança manifestou insatisfação com determinados recursos de interação, como na cena do porco-espinho, em que questionou se o animal poderia ter outras possibilidades de animação 
("Esse bicho só faz isso?"). De acordo com a perspectiva dele, a cena pareceu ter um baixo nível de interatividade. Já no caso de Chomp, foram constatados raros casos de frustração ou desorientação em função dos recursos interativos. A dificuldade de alguns participantes (Gabriel e Elena) em posicionar o rosto na câmera frontal pareceu ter impactado negativamente a leitura em alguns momentos, principalmente porque as crianças desejavam se movimentar com o dispositivo e isso não era possível, já que precisavam permanecer com o rosto centralizado no aplicativo.

\section{Padrões de comunicação verbal}

Como é de se esperar numa situação compartilhada com os pais, houve comunicação verbal entre os participantes. Os pais, no entanto, recorreram muito mais frequentemente à linguagem verbal durante a leitura do que as crianças, que pareciam bastante concentradas no desenrolar da história, assim como na sua própria participação por meio das interações. Como demonstrado anteriormente, os pais usaram frequentemente a linguagem verbal para dar suporte à participação dos pequenos leitores na narrativa, assim como para parabenizá-los quando realizavam a ação corretamente.

Enquanto os pequenos leitores tiveram a tendência a ficar mais calados do que os pais durante a leitura comparti- lhada, algumas vezes respondendo às perguntas dos pais, mas não sempre, é digno de destaque que em diversos casos o leitor infantil usou a linguagem verbal para conversar diretamente com a narrativa, respondendo questões apresentadas pelas personagens no decorrer da história ou fazendo comentários. Esse tipo de resposta foi mais comum na leitura de The Monster at the End of This Book, possivelmente porque a estrutura dessa narrativa é de um diálogo direto com o leitor, mas em Little Red Riding Hood isso também ocorreu. Por exemplo, quando a mãe da Chapeuzinho pergunta se o leitor poderia ajudá-la a empacotar a cesta, Maria respondeu entusiasmadamente: "Yes!" ["Sim!"]

Como mencionado anteriormente, os pais de Gabriel realizaram pequenas intervenções durante a leitura do aplicativo Chomp, para que a criança pudesse centralizar o rosto no dispositivo. Essas intervenções também foram marcadas pela comunicação verbal dos pais que, da mesma forma, se divertiram com as falas encenadas pela criança. Assim, a intervenção dos pais, nesse caso, foi fundamental para que a criança se sentisse motivada a participar criando falas e se comunicando verbalmente com o aplicativo.

Em situações de leitura independente, a comunicação verbal ocorreu principalmente entre a criança e o aplicativo, ora realizando comentários sobre 0 
aplicativo, ora conversando com as personagens. Isso ocorreu, principalmente, nas sessões de leitura de Gabriel com Petting Zoo, nas quais a criança tentou dialogar com a cena em que, interagindo com o tigre, esse tenta caçar uma borboleta; por outro lado, caso o leitor interaja com a borboleta, esta pode "tapear" o tigre e jogá-lo para longe. Gabriel, das diversas vezes que tentou fazer isso, sem nenhuma concretização de seu desejo, fez o seguinte comentário "bicho bobo!", expressando a sua insatisfação. Na leitura independente de Chomp, Elena recorreu à expressão verbal para criar falas e conferir personalidade às personagens que "vestia".

Na primeira leitura de Petting Zoo, no entanto, Gabriel sentiu a necessidade de verbalizar sua experiência e compartilhá-la com o pai. A cada cena, ele mostrava com entusiasmo as possibilidades de interação e o que o animal "podia fazer" ao pai: "Olha pai, o que ele faz!". Em outra situação, quando o menino já havia se ambientado com o aplicativo e havia definido suas personagens favoritas, deslocava-se do sofá até o local em que sua mãe estava para mostrar-lhe os recursos.

No caso da leitura entre pares de Petting Zoo, houve diversos momentos em que se percebeu o diálogo verbal estabelecido entre as irmãs. As crianças tentaram planejar conjuntamente a leitura, numa forma de "colaboração verbal" durante a navegação, transição entre as telas e interações. Uma das situações que pode ser evidenciada é quando Elena, desejando passar para a próxima tela, questiona a irmã com o seguinte enunciado: "Vamos passar?". Em outros casos, as crianças também se comunicavam verbalmente para estabelecer um modo de interação com determinada cena. Isso ocorreu na cena do camaleão, em que as crianças combinaram quais cores iriam pintar (tocar sobre a tela) o corpo do animal. Todavia, na leitura de Chomp, a dinâmica entre as irmãs foi distinta. O diálogo foi bastante marcado pela mediação verbal feita por Elena enquanto Isabella realizava as interações. As crianças se comunicavam, ora para interagir (“Aperta na bola!”, fala de Elena), ora para comentar sobre as possibilidades do aplicativo ("A gente pode ser o que quiser”, percepção de Elena sobre o aplicativo). Enquanto Elena era mais comunicativa, oralizando as suas falas e guiando sua irmã, Isabella, por sua vez, demonstrava timidez no momento de se expressar, tanto durante a leitura como nas suas percepções sobre o aplicativo.

\section{Discussão}

A análise comparativa dos dados indicou que nos aspectos linearidade e incidentes de frustração, a leitura digital apresentou poucas diferenças entre as 
diferentes situações de leitura, enquanto na permanência e exploração do potencial interativo houve certa variabilidade entre as situações. Já o aspecto de comunicação verbal pareceu ser o mais fortemente marcado pelas diferenças entre as situações de leitura.

Em termos da linearidade da leitura, os participantes apresentaram forte tendência a desenvolver uma leitura linear, seguindo a sequência de cenas proposta pelo aplicativo, independentemente de estarem lendo com os pais, de maneira independente, ou entre irmãos. $\mathrm{O}$ fato de o aplicativo apresentar uma narrativa, $o$ que poderia sugerir uma leitura linear, ou não apresentar uma narrativa, o que em tese possibilitaria a livre exploração não linear da obra, sem prejuízo à sua fruição, não pareceu impactar a leitura. Uma possível justificativa para essa tendência é que, por se tratarem das primeiras leituras desses aplicativos e uma vez que a maioria dos participantes em todas as situações não terem grande familiaridade com esse tipo de obra, a leitura linear apresenta uma estratégia natural de navegação até que os leitores tenham dominado a estrutura da obra, bem como suas possibilidades de navegação não linear, como os menus que permitem saltar cenas, que não aparecem tão explicitamente nas obras.

Do mesmo modo, a observação de incidentes de frustração não pareceu estar relacionada às diferentes situações de leitura, e sim ao nível de dificuldade das interações propostas. Mesmo sem o apoio de adultos, as crianças navegaram com fluidez a experiência literária dos aplicativos Petting Zoo e Chomp, que apresentam interações simples e não requerem uma ação específica do leitor para que a interação faça sentido. $\mathrm{Na}$ leitura de Little Red Riding Hood, por sua vez, a complexidade das interações causou maior dificuldade na leitura e na participação na história interativa. Ainda que os pais estivessem atentos e oferecendo suporte constante às crianças, reduzindo as possibilidades de frustração, em alguns (poucos) momentos mesmo os adultos tiveram dificuldade em compreender o que fazer e a frustração, tanto dos pais quanto das crianças, ficou aparente.

Tais resultados referentes à linearidade e frustração leitora divergem do que foi observado por Real e Correro (2015) na leitura doméstica, principalmente em situação independente. Quanto à linearidade, elas observaram, especialmente nas releituras, uma alta fragmentação da leitura digital independente. Tal diferença pode ser resultado, como já discutido, de um design de navegação que privilegia a leitura linear, mesmo no caso de aplicativos sem narrativa. Já no que diz respeito à frustração, o estudo na Espanha observou casos em que a frustração foi tamanha que levou algumas crianças a abandonar o aplicativo, 
o que não ocorreu nos eventos discutidos nesse artigo.

No que diz respeito à exploração das possibilidades interativas das cenas, se percebeu que, em todas as situações de leitura, houve, inicialmente, uma certa falta de iniciativa de grande parte dos leitores infantis em iniciar as interações e explorar as cenas. Isso, provavelmente, se deveu à falta de experiência da maioria desses leitores com os aplicativos literários e até mesmo com a tecnologia digital móvel em geral. Do mesmo modo, algumas formas de interação mais complexas geraram dificuldades para as crianças. Assim, na leitura compartilhada esse suporte veio, naturalmente, dos pais, que ali já estavam posicionados, enquanto na leitura individual e entre pares os adultos que estavam ao redor (em situação de acompanhamento, mas não de compartilhamento), percebendo a dificuldade das crianças, resolveram intervir espontaneamente. No caso em que a pesquisadora interveio na leitura de Elena, essa participação do adulto foi mais pontual, enquanto no caso de Gabriel, a participação dos pais se estendeu, transformando a leitura individual em compartilhada. No entanto, passado esse aprendizado inicial da realização de algumas ações, as crianças do estudo 2 demonstraram ser capazes de ler as obras de maneira independente e de maneira autônoma se detiveram nas cenas e exploraram as possibilidades interativas. No caso do aplicativo Petting Zoo, em que o nível de dificuldade para a realização das interações é baixo, as crianças não precisaram em nenhum momento do suporte de um adulto para a leitura independente. Essas observações parecem estar em sincronia com a pesquisa de Aliagas e Margallo (2015), em que, progressivamente, o suporte do adulto foi diminuindo e as crianças ganharam autonomia para ler e explorar todo o potencial interativo por si próprias. No entanto, a escala temporal para essa mudança, que no estudo Espanhol, a que tudo indica, levou meses, na nossa observação aconteceu quase que imediatamente. Uma vez que do Estudo 2 a proposta era da leitura independente, a negociação da autonomia como uma forma de negociação de poder e agência da criança no contexto familiar não estava em jogo, e após algumas poucas interferências dos pais, as crianças passaram a ser bem-sucedidas na leitura individual.

Na leitura entre pares de Petting Zoo, passada a paralisação inicial, as irmãs colaboraram, lendo e interagindo de maneira conjunta e com essa parceria explorando as possibilidades interativas. Já na leitura conjunta de Chomp, uma vez que a irmã menor, Elena, já havia lido o aplicativo de maneira independente e conhecia as possibilidades interativas, as irmãs estabeleceram papéis distintos, com Elena guiando as interações, 
realizadas por Isabella. Essa dinâmica demonstra que a experiência do leitor pode ser mais determinante que sua idade para a realização de uma leitura completa e aprofundada das possibilidades interativas das obras.

$\mathrm{O}$ aspecto da comunicação verbal foi marcadamente o elemento com maior variação entre as situações de leitura observadas, porém, mesmo na situação de leitura independente, os leitores se expressaram verbalmente, em grande parte se endereçando à obra e às personagens. As funções da comunicação verbal variaram entre as diferentes situações. Na leitura compartilhada com os pais, houve um predomínio da fala dos adultos endereçada à criança, em grande parte com a função de dar suporte à leitura, ensinando e incentivando a interação e expandindo a narrativa com comentários e questões, enquanto as crianças estavam mais concentradas nas ações. Na leitura entre pares, também houve instâncias em que a leitora que realizava a interação permaneceu mais calada que a coleitora, que fazia comentários, mas a linguagem verbal também foi usada de maneira colaborativa para negociar a leitura compartilhada.

Os resultados da leitura entre pares estão em sintonia com a teoria de Maine (2015), acerca da leitura dialógica, que indica a linguagem verbal como essencial na negociação de significados na leitura entre pares. Já na leitura individual, a comunicação entre leitor e obra que se manifesta pela interação também ocorreu pela linguagem verbal. Todavia, no caso de Gabriel, houve ainda uma tendência a socializar sua leitura individual com os pais, que estavam no ambiente, mas, inicialmente, não participavam da leitura, o que reforça a importância do compartilhamento das experiências de leitura da criança, como sugerido por Kucirkova, Littleton e Cremin (2016).

\section{Considerações finais}

Os resultados desse estudo comparado são de grande utilidade para pais e educadores na reflexão sobre os usos e experiências com a literatura digital em contextos formais de educação, como a pré-escola e a escola, como em contextos informais, como a leitura em ambiente doméstico.

Primeiramente, indicam que os diversos modos de leitura apresentam oportunidades ricas de leitura na infância e que essa diversidade deve ser promovida durante o desenvolvimento das crianças enquanto leitores literários, tanto em casa como na escola. Em todas as situações de leitura, as crianças demonstraram grande engajamento com as obras, o que é fundamental para o desenvolvimento do prazer de ler. Nas diferentes situações descritas e analisadas, foi possível observar o empenho das crianças em encontrar 
soluções interpretativas que levassem à construção de sentido, apoiando-se, por vezes, nas estratégias de leitura dos pais, ou irmãos, ou desenvolvendo o seu próprio caminho de leitura. Os resultados demonstraram também, que a leitura independente pode oportunizar o aprofundamento da educação literária e desenvolver a autonomia do leitor infantil. Joy D. Erickson e Ruth Wharton-McDonald (2018) alertam para a necessidade do desenvolvimento de uma "motivação autônoma" para a leitura, a fim de sustentar o hábito de ler ao longo da vida da criança. Sugerimos que, para que a criança desenvolva esse tipo de motivação, a leitura independente é fundamental, e com o suporte multimídia dos aplicativos literários, ela pode ocorrer em sua completude mesmo antes de a criança ter o domínio da decodificação do texto escrito. Os resultados, no entanto, também indicam que nas leituras que desafiam o leitor e/ou apresentam um design de interação complexo, o suporte dos pais pode ser essencial para evitar a frustração do pequeno leitor e uma leitura altamente fragmentada, como observada por Real e Correro (2015), prejudicando a construção de sentido e desengajando a criança na leitura digital.

Ainda que a mediação do adulto seja importante no processo de construção de sentido do texto, ressalta-se, neste trabalho, o aspecto positivo da leitura entre pares. Este estudo concluiu que, quando há a presença de uma outra criança durante a leitura, essa se torna mais fluida, na medida em que as experiências individuais dos leitores podem se complementar. Visto que os eventos de compartilhamento de leitura entre pares é algo construído naturalmente, via relações sociais e afetivas, a leitura pode se transformar em um processo mais espontâneo e prazeroso, em que a exploração, seja por meio de gestos ou falas, promove a solução dos desafios e inconsistências do texto.

\section{Reading situations of digital literature in the early years: characteristics of independent reading, children reading together and children reading with parents}

\section{Abstract}

The objective of this work is to compare the characteristics of three reading situations of preschoolers engaged with literary apps: independent reading, children reading together and children reading with their parents. The data derived from two qualitative studies that investigated children's responses to digital literature. The first study observed six families of 4-year-olds living in England reading with their parents the apps Little Red Riding Hood (2013) and The Monster at the End of This Book (2011). The second study observed two families of 3 to 7-year-olds in Brazil reading Petting Zoo (2013) and Chomp (2016) during the prac- 
tices of independent and shared reading between siblings (peer reading). Four aspects of the reading situations were compared: the linearity of the readings, the exploration of the interactive functions, the incidence of frustration and the patterns of verbal communication.

Keywords: Digital literary reading; Reading situations; Shared-reading; Early Years; Digital children's literature.

\section{Notas}

1 É importante ressaltar que nem todos os aplicativos fazem uso da linguagem verbal em sua expressão literária, como será visto em dois dos aplicativos analisados neste estudo. Assim, o conceito de "literário" assumido por esse projeto transcende a palavra escrita.

2 Alguns exemplos desse tipo de abordagem pela mídia podem ser vistos em: "Infância digital" $<$ https://pt.aleteia.org/2018/04/06/infancia-digital/>; Tablets e smartphones utilizados como "babás eletrônicas"<https://noticias. r7.com/saude/especialistas-alertam-pais-que-usam-tablets-e-smartphones-como-babas-dos-filhos-21042013>.

3 Aqui estamos diferenciando o uso acompanha$d o$, quando os pais estão juntos ou próximos à criança no momento do uso, supervisionando o que a criança faz e eventualmente ajudando quando há dificuldade, mas sem efetivamente participar da atividade, do uso compartilhado, quando pais e crianças estão conjuntamente engajados na atividade, com os pais acompanhando cada passo.

4 A pesquisa envolveu 2.172 brasileiros que acessam a internet, possuem smartphone e são pais de crianças de 0 a 12 anos e indicou que $23 \%$ das crianças entre 4 e 6 anos tem smartphone próprio e $61 \%$ não tem smartphone próprio mas usa o dos pais. Agradecemos a Fernando Paiva, por ter compartilhado os dados referentes a crianças de 4 a 6 anos exclusivamente, originalmente não publicados no relatório.

5 Ainda que a proposta inicial fosse de observar as crianças lendo sem a participação dos adultos, houve casos em que essa interferência ocorreu naturalmente (ver análise dos dados a seguir).

6 Esse estudo analisou aplicativos para crianças em geral, sem se concentrar no literário.

7 Neste estudo participaram 4 pares de crianças do primeiro ano escolar do sistema inglês ( 6 anos) e três pares de crianças do sexto ano (11 anos).

8 O projeto foi elaborado e submetido no mês de junho de 2016, sendo aprovado em julho do mesmo ano (CAAE: 56844416.1.0000.5349).

9 Palavra relacionada ao zapeamento que significa alterar e alternar de uma fonte de informação para outra. Isso pode ocorrer principalmente quando estamos assistindo televisão e navegando pela internet e acessando as redes sociais ao mesmo tempo (VEEN; VRAKKING, 2009).

\section{Referências}

ALIAGAS, C.; MARGALLO, A. M. iPads, emergent readers and families. In: MANRESA, M.; REAL, N. (Ed.). Digital literature for children: texts, readers and educational practices. Bruxelas: Peter Lang, 2015. p. 155-171.

BARTHES, R. Image, music, text. Londres: Flamingo, 1984.

BERA - BRITISH EDUCATIONAL RESEARCH ASSOCIATION. Ethical guidelines for educational research. Londres: British Educational Research Association, 2011.

BUS, A. G.; VAN IJZENDOORN, M. H.; PELLEGRINI, A. D. Joint book reading makes for success in learning to read: a meta-analysis on intergenerational transmission of literacy. Review of Educational Research, v. 65, n. 1, p. 1-21, 1995.

ERICKSON, J. D.; WHARTON-MCDONALD, R. Fostering autonomous motivation and early literacy skills. The Reading Teacher, v. 72, n. 4, p. 475-483, 2018.

FITTIPALDI, M.; RIVAS, C. D. La literatura como experiencia compartida. Lectura y Vida, 2010. 
FREDERICO, A. Embodiment and agency in digital reading: preschoolers making meaning with literary apps. Tese (Doutorado em Educação) - Faculdade de Educação, Universidade de Cambridge, Cambridge, 2018.

HALLIDAY, M. A. K. Language as social semiotic: the social interpretation of language and meaning. Londres: Edward Arnold, 1978.

HEATH, S. B. Ways with words: language, life, and work in communities and classrooms. Cambridge: Cambridge University Press, 1983.

HIRSH-PASEK, K. et al. Putting education in "educational" apps. Psychological Science in the Public Interest, v. 16, n. 1, p. 3-34, 2015.

KUCIRKOVA, N.; LITTLETON, K. The digital reading habits of children: a National survey of parents' perceptions of and praatices in relation to children's reading for pleasure with print and digital books. Londres: BookTrust, 2016. Disponível em https://www.booktrust. org.uk/globalassets/resources/research/ digital_reading_survey-final-report-8.2.16. pdf.

KUCIRKOVA, N.; LITTLETON, K.; CREMIN, T. Young children's reading for pleasure with digital books: six key facets of engagement. Cambridge Journal of Education, v. 3577, p. 1-18, 2016.

MAINE, F. Dialogic readers: children talking and thinking together about visual texts. Londres: Routledge, 2015.

MEEK, M. How texts teach what readers learn. Stroud: Thimble Press, 1988. 